\title{
ON THE DIMENSIONS OF E-GOVERNMENT INTERACTIONS
}

\author{
Mysore Ramaswamy, Southern University, mysore@acm.org \\ Audrey N. Selian, Wireless Grids Corporation, aselian@hotmail.com
}

\begin{abstract}
The way in which governments interact with their constituents has radically changed due to the recent innovations in information and communication technology (ICT). In spite of the considerable literature on digital or e-government, a clear understanding of the dimensions along which the success of automating government-constituent interactions can be measured is still lacking. This is a critical issue as it has a direct bearing on the very effectiveness of e-governance. Without some method of categorization and assessment, the formation of good policy and planning capable of leveraging the existing capacity of institutions to deliver public service is simply not feasible. In this paper, the dimensions of interactions that occur between a government and its various constituents are analyzed through a variety of modeling techniques. The exercise of restructuring government processes to make them more amenable to automation is also explored through an integrated approach that combines the key elements of three modeling techniques.
\end{abstract}

Keywords: e-Governance, e-Government, e-Task Complexity, Interaction Analysis

\section{INTRODUCTION}

The way in which governments interact with their constituents has radically changed due to the recent innovations in information and communication technology (ICT). In spite of the considerable literature on digital or e-government, a clear understanding of the dimensions along which the success of automating government-constituent interactions can be measured is still lacking [3]. This is a critical issue as it has a direct bearing on the very effectiveness of e-governance. In this paper, the interactions that occur between a government and its various constituents are analyzed using a variety of modeling techniques. The possibility of restructuring government administrative and bureaucratic processes to make them more amenable to automation is also explored.
In this paper, we use the term "e-governance" in a broad sense to include a deeper understanding of the way ICTs impact the existing (and potential future) interactions between a government and its constituents. In other words, e-governance goes beyond the 'what' of an e-government interaction that presumably delivers service to a constituent - and includes rather an analysis of the 'how' and 'why'. We note that one cannot improve upon something in automation that is not already rational and functional in its current daily practice. In spite of tremendous innovations in the field of information technology (IT), the benefits of this progress have not reached all segments of our society, particularly in the case of developing and transition states [3, 12]. Most governments across the world desire their citizens and businesses to interface with them through electronic means for the obvious reasons of efficiency in cost-saving and effectiveness. Whether the transparency in process and information-sharing that this presupposes is also an equally important objective for all leaders is a less obvious assertion. As Jane Fountain states in her work, there is a certain element of the 'perversity of incentives' to acknowledge here; Kedzie calls this the "Dictator's Dilemma" in the state [1] - where increased efficiency and political efficacy (brought about by ICTs) are positively related to each other, and negatively related to authoritarian and highly centralized control. That said, of course, the clear exponential increases in numbers of Internet users around the world during the last two decades $[13,15]$ are a strong indicator of the likelihood of increases in demand for such ICT-enabled services within the confines of respective political systems.

The rest of this paper is organized as follows. The next three sections discuss the following eGovernment models respectively: Design Reality Gap Model, Agent-Service-Discretion Model, and EGovernance Cube. The subsequent section attempts to integrate the above approaches and proposes a methodology to achieve more relevant e-governance. The conclusions and future research directions are presented in the last section. 


\section{DESIGN-REALITY GAP MODEL}

The objective of Design-Reality Gap Model proposed by Heeks [7] is to evaluate the amount of change between 'where we are now' and 'where the egovernment project wants to get us.' The structure of this model is indicated in Appendix I. In this approach, e-government projects are analyzed along the following seven dimensions:

- Information,

- Technology,

- Processes,

- Objectives and Values,

- Staffing and Skills,

- Management Systems and Skills, and

- Other Resources: Time and Money.

Using each of the seven dimensions, the following two factors are analyzed: first, the organizational reality relating to the dimension that exists right now at the time of analysis (i.e. current snapshot); and second, the requirements within the design of the egovernment application.

The next step is to give a numerical rating to each of the above dimensions in order to indicate the size of the design-reality gap on that dimension. For example, taking the first dimension - information - 0 would indicate that the information used in the egovernment application was exactly the same as the information currently being used in the given organization. 5 would indicate that the information used in the e-government application was somewhat different from the information currently really being used. 10 would indicate that the information used in the e-government application was completely and radically different from the information currently really being used.

Putting the above seven dimensions together with the notion of gaps produces a model capable of understanding the relative success or failure of egovernment initiatives. In its simplest form, the model yields a cumulative score based on the rating numbers for all the seven dimensions. A more complex variation would involve two rounds. To begin with, the risk assessment team would assign a weight to each of the dimensions. Then the weighting score would be multiplied by the rating to give an overall set of weighted ratings, the sum of which is used as an indicator of success or failure.

If nothing else, this is a valuable tool and method for assessing whether the current institutional capacity of a given organization is capable of living up to its own service mandate. This is assuming, of course, that any large discernible gaps between 'design' and 'reality' are reflective of an absolute commitment of $\mathrm{e}$ government application designers to the development of clear, effective automated solutions, without bias. This is in contrast perhaps to what some believe are the natural, gravitational tendencies of governmentsupported/subsidized human organization (particularly in developing countries) to subvert the simplicity of service delivery in a quagmire of bureaucratic and corrupt activity for personal gain. This makes sense insofar as it reflects a phenomenon to be observed in most places where human resource incentives structures are too weak to ensure the contrary (that is, a smaller gap between design and reality).

\section{AGENT-SERVICE-DISCRETION MODEL}

Naarmala has proposed an Agent-Service-Discretion Model to cover all scenarios of e-Government interactions [11]. This is a variation of the ecommerce model proposed by Choi [5]. The three axes in that model refer to player, product and process.

In the model proposed by Naarmala [Appendix II], the $\mathrm{x}$-axis refers to an agent of e-government interaction. This entity can be a public officer, either physical or online. The y-axis represents the presence of service including delivery. The range extends from the mostly physical, to the mostly online. The z-axis refers to discretion or the degree of freedom over decision-making. Nearer to the origin indicates highly structured or rule-bound procedures, whereas farther from the origin refers to interactions that invoke a high degree of discretion. This type of analysis provides a way to compare e-government interactions with that of classical e-commerce interactions.

This model provides a way to analyze various activities based on the degree of the three dimensions required to execute that particular activity. For example, a case where a customer is dealing with an officer face-to-face and the actual decision made is strictly rule bound and regulated indicates a situation where all the three dimensions (agent, service, and discretion) are physical. Different scenarios that occur due to different mixes of the three dimensions can be viewed as development phases from traditional administrative services towards pure, virtual public e-services.

Several semi-stages on the way towards pure public e-services can be analyzed using this framework. 
These interactions include both service and agent being online, and the degree of discretion occurring in various degrees.

The main advantage of this model is that it presents a more nuanced way of analyzing governmentconstituent interactions, taking into consideration the element of 'degrees of freedom' over decisionmaking. This critical aspect of measurement is missing in the previous model.

\section{E-GOVERNANCE CUBE}

Government-to-citizen (G2C) interactions of eGovernment comprise a very significant component in the formation of a truly inclusive and functioning e-society. In this context, we need to address the following questions:

- How can we make e-Government truly citizencentric?

- Do we have objectives that are realistic?

- How well are we achieving these objectives fully and cost-effectively?

- Are these objectives jointly determined and agreed upon by citizens and their government agencies?

We need better models to plan, fund, develop, implement, operate, and evaluate successful eGovernment across various political and social, cultural, and economic contexts [4]. Above all is the necessity for such models to be able to acknowledge and adjust to the idiosyncrasies of specific cases.

Some of the above concerns are addressed by the eGovernance cube model. Ramaswamy and Selian [12] propose the formation of an e-Governance cube with the following three axes: entity type on the $\mathrm{x}$ axis, processing complexity on the $\mathrm{y}$-axis, and perceived value on the z-axis as shown in Appendix III. These parameters are based on the principles that define quality of information [16].

In the e-Governance cube, government-to-constituent interactions are categorized into three groups: government-to-government (G2G), government-tobusiness (G2B), and government-to-citizen (G2C). This categorization is useful for analyzing differences in the types of information needs typically necessary for the successful execution of specific types of service delivery. The entity type is represented on the $\mathrm{x}$-axis.

Processing complexity is represented on the y-axis. The processing complexity of an interaction is a function of the information available as to how to execute that task. Focusing on the information required for processing an e-governance transaction, we can combine relevance, accuracy and precision, and define correctness as an attribute that refers to the accuracy and relevance of the information provided, while adding in some way to the successful execution of the task. In addition to correctness, we find that the following three attributes are necessary and sufficient to capture its utility: completeness, clarity, and ease of accessibility. The adequacy of available information to process the task is captured by the term 'completeness'. 'Clarity' is the expectation that the information provided is in a form that is easy to understand. 'Ease of accessibility' indicates the ease with which people who need it can find and access that information. Each attribute is measured in turn on the binary basis of values set between 0 and 1,0 referring to the absence of these attributes, and 1 referring to their presence.

Users' or constituents' perceptions of the value of egovernance interactions play a key role in assessing the level of resistance in government to restructuring, and the subsequent automation of bureaucratic procedures already in place. This dimension of perceived value is represented on the z-axis. The range of this axis is divided into three simple parts: low (L), medium (M) and high (H). Thus, the interactions towards the top of the cube have a higher perceived value. Accordingly, the volume of government-constituent interactions will increase when the perceived value of such interactions is deemed higher, or more 'valuable'. Defining these ranges for the axes in this way enables the division of the e-governance cube into 27 sub-cubes. Appendix III indicates a government-to-citizen interaction of processing complexity $\beta$, and of perceived value of medium range $(C, \beta, M)$ being transformed to an interaction of lesser processing complexity $\alpha$.

The e-governance cube provides a means of evaluating an extensive (if not comprehensive) series of government-constituent interactions. Depending upon which of the 27 sub-cubes contains the given transaction of interest, we are now able to make inferences on the potential of that transaction for its ease of conversion to e-governance. This naturally opens up a wide arena of analysis, particularly for others who wish to specialize and focus specifically on the dynamics and characteristics of very specific e-governance transactions. In the context of the egovernance cube model, the further one moves away from the origin, the more resistance one is likely to encounter to automation. From the e-inclusion point of view, the processes that are valued high on the zaxis (perceived value) need to be addressed first. 


\section{AN INTEGRATED APPROACH}

The main objective of analyzing the dimensions of egovernment interactions is to improve the effectiveness of e-governance as a system. It is to be noted that placing an IT layer over and automating a faulty bureaucratic system may yield a more efficient system, but will certainly not be one desired by or responsive to its core constituents. The analysis as undertaken by using the e-governance models described in this paper will yield a better understanding of the government-constituent interaction in terms of processing complexity, as well as the degree of importance attached to that interaction by the constituent.

By integrating key elements of the three models described in the preceding sections, the following framework can be used to initiate the process chain that transforms conventional bureaucratic tasks to egovernment interactions:

Step 1: Using the design-reality-gap model, ascertain the gap that exists between the status quo and the ideal design in critical areas such as information, technology, and processes.

Step 2: Using the agent-service-discretion model, identify the task to be automated in terms of agent (physical or online), service (physical or online), and discretion (degree of freedom over decision making).

Step 3: Using the e-governance cube, identify the egovernance potential of the subject task by considering the dimensions of entity type, processing complexity and perceived value to the constituent.

The range of government-constituent interactions is indeed very large as evidenced by the three stakeholder groups of constituents (citizen, business, and government). The gamut of interactions is also very diverse. It is critical that these interactions are properly restructured before being automated $[8,12]$.

One of the major advantages of analyzing the interactions from the dimensional perspective irrespective of the specific model used - is the help this lends to the process of restructuring. For example, using the e-Governance Cube, restructuring a process that is at a distance from the $\mathrm{x}$-axis (higher complexity as well as perceived value) requires far more attention than a process that is less complex and having lower perceived value.

\section{CONCLUSION}

Interactions between the government and its constituents are the basic building blocks of egovernment. In this paper, we have presented and analyzed differing modeling techniques that shed light on diverse aspects of these interactions. The several dimensions of the Design-Reality Gap Model set a contextual framework under which we need to build improvements. The Agent-Service-Discretion Model focuses on the degree of discretion that is required from the governmental agent - whether physical or online - and thus provides a needed perspective. The essentials of information processing are embedded in the e-governance cube and this modeling technique provides an easy approach towards process restructuring. However, a comprehensive modeling framework that incorporates all critical dimensions discussed above and also facilitates process restructuring is still lacking.

The future work in this area focuses on integrating the three modeling techniques to one comprehensive framework. Such a framework will enable policy makers and researchers to point out the potential priority areas that need to be automated first and also yield a realistic estimate of resources needed to achieve such transformation. In addition, such an approach will also help process restructuring.

\section{REFERENCES}

1. Allison, Juliann Emmons. (2002) Technology, Development, and Democracy: International Conflict and Cooperation in the Information Age. Albany: State University of New York Press.

2. Alter, S. (2002) Information Systems: Foundations of E-Business. Prentice Hall, Upper Saddle River, NJ.

3. Carbo, T. and Williams, J. (2004). Models and Metrics for Evaluating Local Electronic Government Systems and Services. The Electronic Journal of Electronic Government, Vol. 2, No. 1, pp. 99-106.

4. Carbo, T. and Williams, J. G. (2004). "Some Determinants of User Perceptions of Information Quality on the World Wide Web," Electronic Journal of e-Government, Vol. 2, No. 2 pp. 94105.

5. Choi, S. et al. (1997). The Economics of Electronic Commerce, Macmillan Technical Publishing, Indianapolis. 
6. Fountain, Jane E. (2001) Building the Virtual State: Information Technology and Institutional Change. Washington, DC: Brookings Institution Press.

7. Heeks, R (2003). "Causes of eGovernment Success and Failure: Design Reality Gap Model," http://www.e-devexchange.org/ eGov/ causegap.htm

8. Homburg, V. and Bekkers, V. (2002) "The Back-Office of E-Government," Proceedings of the 35th Hawaii International Conference on Information Systems, (9 pages).

9. Kuzmin, A. (2003). "The Two Dimensions of eGovernment: Potential and Use," WwW. processconsulting. ru/ doc/ Two dimensions_of_e-Government.pdf

10. McLeod, R. and Schell, G. (2001) Management Information Systems. Prentice Hall, Upper Saddle River, NJ.

11. Naarmala, J. (2004). "Going Digital Explaining Dimensions of eGovernment," www.ebrc.info/ pages_ C86FCC043314-4DF9-9AE2-138286 0CB17F.asp

12. Ramaswamy, $M$ and Selian, A. (2007). eGovernment in Transition Countries: Prospects and Challenges, Proceedings of the 40th Hawaii International Conference on Information Systems, (10 pages).

13. Scholl, H. J. (2003) "E-Government: A Special Case of ICT-enabled Business Process Change," Proceedings of the 36th Hawaii International Conference on System Sciences, (12 pages).

14. Turban, E. et al, Electronic Commerce: A Managerial Perspective, Prentice Hall, Upper Saddle River, NJ, 2004.

15. Wimmer, M. R. et al (2001) "Electronic Business Invading the Public Sector: Considerations on Change and Design" Proceedings of the 34th Hawaii International Conference on System Sciences, (10 pages).

16. Zmud, R. W. (1978) “An Empirical Investigation of the Dimensionality of the Concept of Information," Decision Sciences (9), pp. 187195.

\section{APPENDIX I.}

Design-Reality Gap Model (Adapted from [7])

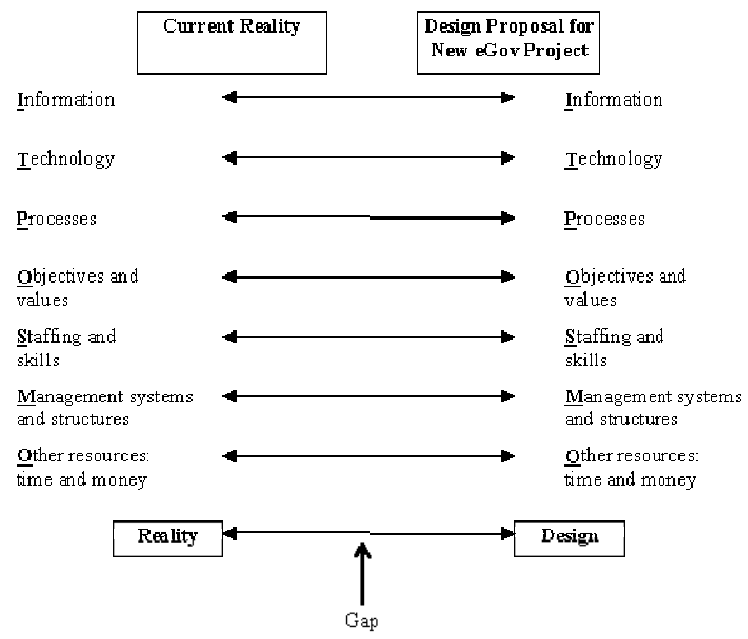

APPENDIX II.

Agent Key:

Physical

Hybrid

Online

Service Key:

Physical

Hybrid

Online

Discretion Key:

R: Rule-bound

$\mathrm{H}$ : Hybrid

D: Discretion

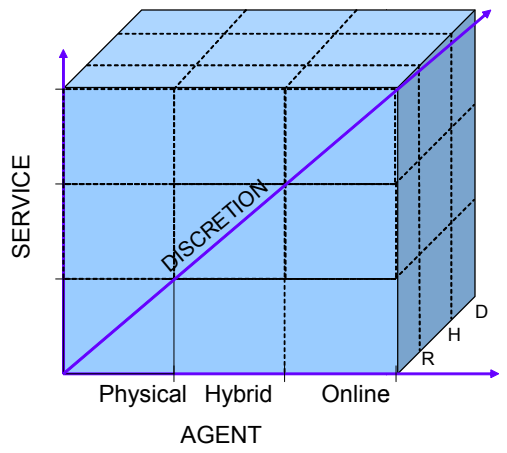




\section{APPENDIX III.}

E-Governance Cube (Adapted from [12])

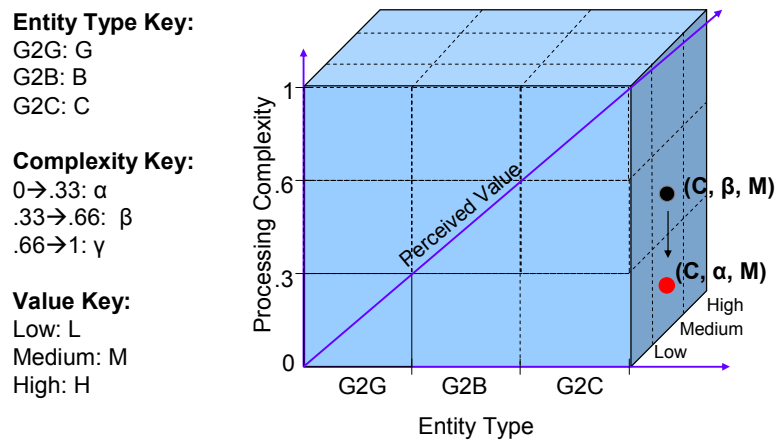

